\title{
ANSYS ANALYSIS OF STRESS AND STRAIN AFTER CONES PLASTIC DEFORMATION
}

\author{
Krzysztof Rokosz, Tadeusz, Hryniewicz, Winfried Malorny, Jan Valiček, Marta Harničárová
}

Preliminary notes

The paper deals with study of stress and strain after cones plastic deformation by ANSYS software. There are shown the new results of FEM analysis, what is the base for the further experimental studies.

Keywords: ANSYS analysis; carbon steel C45; cones shape; plastic deformation

ANSYS analiza naprezanja i deformacije nakon plastične deformacije konusa

Prethodno priopćenje

Rad se bavi proučavanjem naprezanja i deformacija nakon plastične deformacije konusa pomoću ANSYS softvera. Prikazani su novi rezultati FEM analize, što je osnova za daljnje eksperimentalne studije.

Ključne riječi: ANSYS analiza; konični oblik; plastična deformacija; ugljični čelik C45

\section{Introduction}

Numerical analysis of non-linear plastic deformation especially by rolling $[1 \div 6]$ with the appointment of team working on stress and strain analysis $[7 \div 12]$ was studied. It was also possible to find a solution of contact problem of movable elasto/visco-plastic body [8] and thermal numerical analysis in deformation zone $[9,10]$ as well as mathematical modelling of deformation of the asperity in the burnishing rolling operation [11]. Based on the available literature on the theory of solid mechanics and finite-element method $[14,15,16]$ the authors proposed in this paper the cone deformation analysis using a simulation experiment in ANSYS. The simulation analysis presented below will be performed in the future as experiment using a strain-stress machine. Then, during these measurements, the additional analyses such as noncontact methods of surface analysis [17], measurements uncertainties [18], etc., will be performed. Moreover there is planned a comparison of the stress and strain results after cold rolling of flat plates [18] with other ones concerning e.g. triangle and/or trapezoidal cross sections.

Deformation is characterized by the change in mutual displacement of points on the solid surface due to the action of applied loads. There is an elastic deformation which vanishes just after removal of the load, as well as the plastic/firm deformation which remains after load removal.

The deformation state is characterized by linear and angular deformations (Fig. 1). The linear deformation occurs e.g. during extending the rod of a uniform square cross-section due to a normal stress (Fig. 1a). If the deformation is determined from the dependence:

$\varepsilon=\frac{l_{\mathrm{c}}-l_{0}}{l_{0}}$,

where: $l_{0}$ and $l_{\mathrm{c}}$ - initial and transient/temporary rod length so they are determined as relative/apparent deformations.
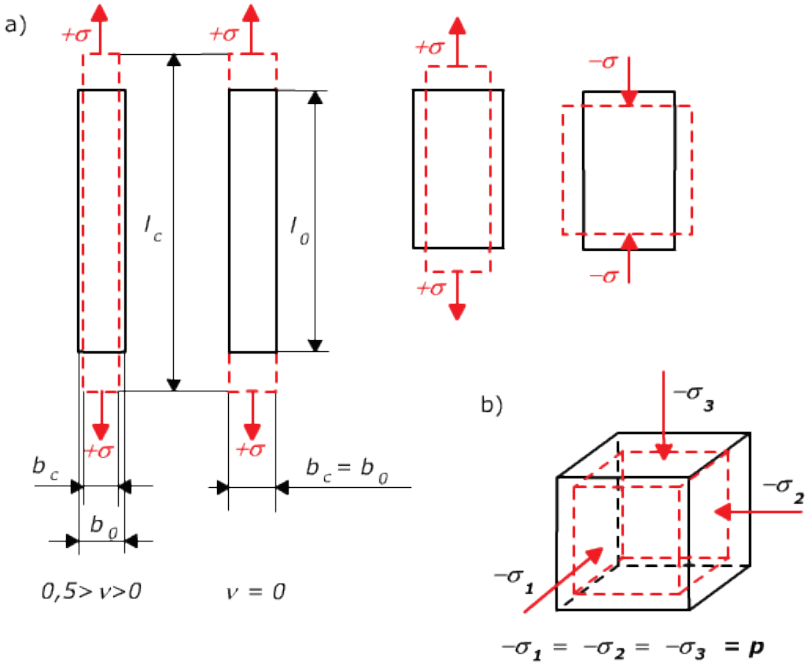

Figure 1 Deformation schematics: a) one-axis extension and compression, b) hydrostatic compression [13]

In practice, the relative deformations are usually given in per cent:

$\varepsilon=\frac{l_{\mathrm{c}}-l_{0}}{l_{0}} 100, \%$

The deformation $\varepsilon$ is an apparent characteristic because while it's determining no continuous change in the rod length is regarded during the deformation. The real deformation $\varepsilon_{\mathrm{rz}}$, called the logarithmic deformation, in the opposition to the relative deformation $\varepsilon$, reflects the physical meaning of deformation.

It may be confirmed basing on the following example: if during the extension the initial length of rod $l_{0}$ is increased up to $2 l_{0}$, and during compressing $l_{0} / 2$, the relative deformations are equal in both cases as to the value and opponent/adverse as to the sign. In such conditions under extension:

$\varepsilon=\frac{2 l_{0}-l_{0}}{l_{0}}=1$, 
$\varepsilon_{\mathrm{rz}}=\ln \frac{2 l_{0}}{l_{0}}=\ln 2=0,69$,

and under compression:

$$
\varepsilon=\frac{\frac{l_{0}}{2}-l_{0}}{l_{0}}=-0,5,
$$$$
\varepsilon_{\mathrm{rz}}=\ln \frac{\frac{l_{0}}{2}}{l_{0}}=\ln \frac{1}{2}=\ln 1-\ln 2=-\ln 2=-0,69 .
$$

Evaluation/estimation of the deformation state in any point of the body relies on determination of the length change between the point and any other neighbouring point and the change of angle between two directions coming out of the same point, occurring as the result of deformation. Relative deformations in the directions $x_{1}$ and $x_{2}$ are described by the equations:

$$
\frac{\left(u_{1}+\frac{\partial u_{1}}{\partial x_{1}} \mathrm{~d} x_{1}\right)-u_{1}}{\mathrm{~d} x_{1}}=\frac{\partial u_{1}}{\partial x_{1}}, \frac{\left(u_{2}+\frac{\partial u_{2}}{\partial x_{1}} \mathrm{~d} x_{1}\right)-u_{2}}{\mathrm{~d} x_{1}}=\frac{\partial u_{2}}{\partial x_{1}} .
$$

Under introducing the third axis $x_{3}$ there will be the third relative deformation $\partial u_{3} / \partial x_{1}$. Additionally, there are two angular deformations $\partial u_{1} / \partial x_{2}$ and $\partial u_{1} / \partial x_{3}, \partial u_{2} / \partial x_{2}$ and $\partial u_{2} / \partial x_{3}$ as well as $\partial u_{3} / \partial x_{2}$ and $\partial u_{3} / \partial x_{3}$ against each of the three axes. These deformations form a tensor of relative deformations $[14,15,16]$ :

$$
\frac{\partial u}{\partial x}=\left[\begin{array}{lll}
\frac{\partial u_{1}}{\partial x_{1}} & \frac{\partial u_{1}}{\partial x_{2}} & \frac{\partial u_{1}}{\partial x_{3}} \\
\frac{\partial u_{2}}{\partial x_{1}} & \frac{\partial u_{2}}{\partial x_{2}} & \frac{\partial u_{2}}{\partial x_{3}} \\
\frac{\partial u_{3}}{\partial x_{1}} & \frac{\partial u_{3}}{\partial x_{2}} & \frac{\partial u_{3}}{\partial x_{3}}
\end{array}\right] \text { or } e_{i j}=\left[\begin{array}{lll}
e_{11} & e_{12} & e_{13} \\
e_{21} & e_{22} & e_{23} \\
e_{31} & e_{32} & e_{33}
\end{array}\right]
$$

Values and types of stresses depend first of all on the processes of deformations and cracking. In the studies of mechanical properties the characteristics of the stress state in each point of the body are necessary. The values of stresses existing in each cross-section coming through the point should be known. Taking into consideration the whole body volume one may separate just a tiny parallelepiped with the edges forming rectangular coordination system of axes marked as $x, y, z$ or $x_{1}, x_{2}, x_{3}$ (Fig. 2).

In a general case, the mutually balanced stresses which may be easily distributed onto one normal and two tangent components, act on its three non-parallel faces. Each component is marked by two indexes. The first index of the stress denotes the plane on which the stress acts $(x, y, z$ or $1,2,3)$, and corresponds with the index of axis perpendicular to this plane, the second one denotes the direction of stress action $(x, y, z$ or $1,2,3)$.

All the occurring components of stress ( 3 normal and 6 tangent) acting in the faces of elementary parallelepiped fully determine the stress state in any point.

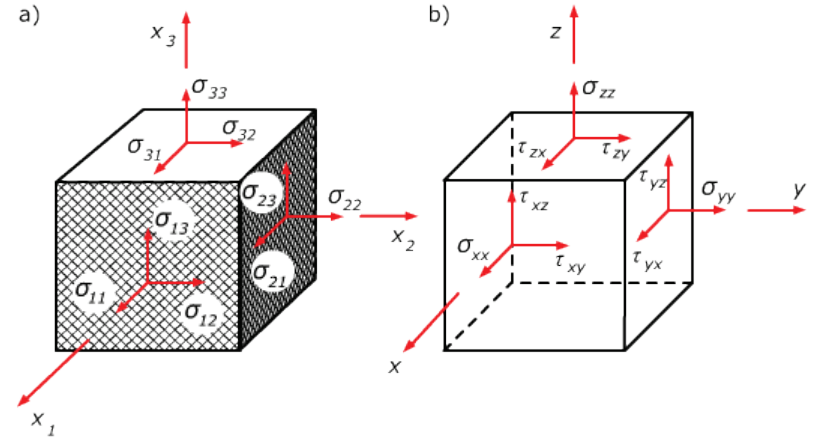

Figure 2 Schemes of stress determination in the point of coordination system: a) $x_{1}, x_{2}, x_{3}$; b) $x, y, z[13]$

They may be presented in the form of matrix, called the stress tensor:

$T_{i j}=\left[\begin{array}{ccc}\sigma_{x x} & \tau_{x y} & \tau_{x z} \\ \tau_{y x} & \sigma_{y y} & \tau_{y z} \\ \tau_{z x} & \tau_{z y} & \sigma_{z z}\end{array}\right], \sigma_{i j}=\left[\begin{array}{ccc}\sigma_{11} & \sigma_{12} & \sigma_{13} \\ \sigma_{21} & \sigma_{22} & \sigma_{23} \\ \sigma_{31} & \sigma_{32} & \sigma_{33}\end{array}\right]$,

where: $\sigma_{i j}$ for $i=j$ (e.g. $\left.\sigma_{x x}, \sigma_{22}\right)-$ normal stresses, $\sigma_{i j}$ for $i$ $\neq j$ (e.g. $\left.\sigma_{x z}, \sigma_{31}\right)-$ tangent stresses.

Conditions of equilibrium of a body require the summary rotary moment against each of the three coordination axes to be zero. From this, the rule of pairs of tangent stresses results: the symmetric components against the general diagonal of tensor must possess simultaneously identical in pairs absolute values with their turns directed to the common edge or from it $\left(\tau_{21}=\right.$ $\left.\tau_{12}, \tau_{31}=\tau_{13}, \tau_{32}=\tau_{23}\right)$. Inequality $\tau_{i j}=\tau_{j i}$ means arising of a rotary moment against the axis $x_{3}$ (Fig. 3 ).

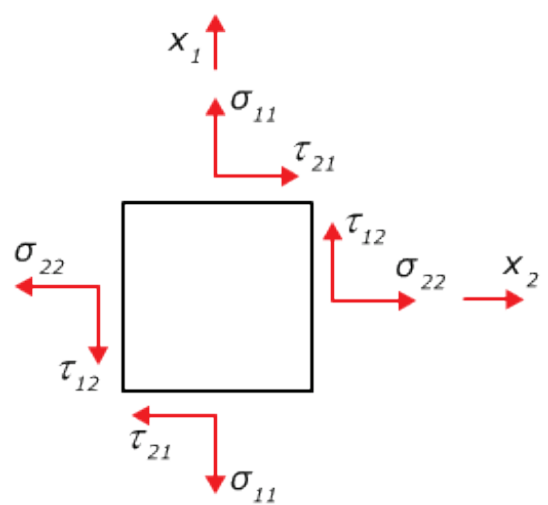

Figure 3 Scheme of positioning of tangent components of stress $\tau_{12}$ and $\tau_{21}[13]$

This rule has the essential meaning in formulating conditions of equilibrium of a solid in the studies of mechanical properties (stress state) because the processes with the tangent stresses occur in two groups of the mutually perpendicular planes. The studies of stress state rely mainly on the determination of normal stresses because they are used in calculations of design strength.

It results from the theory of elasticity and plasticity that one may draw three mutually perpendicular planes through each of the solid point being under the state of stresses; they are called the general planes in which the normal stresses attain the extremum values $\left(\sigma_{\max }, \sigma_{\min }\right)$, with no tangent stresses occurring. Axes of the 
coordination system determined by straight/lines of intersections of these planes are the general directions and the stresses acting in the direction of these axes are called the general stresses $\left(\sigma_{11}, \sigma_{22}, \sigma_{33}\right)$. They are denoted usually in a simpler manner: $\sigma_{11} \rightarrow \sigma_{1}, \sigma_{22} \rightarrow \sigma_{2}, \sigma_{33} \rightarrow \sigma_{3}$. In the mechanical studies the general directions are known, e.g. under axial tension, pressing ball into the material surface during the hardness measurement; they may be assumed as the coordination axes. Taking into account the general coordinates, the tensor of stresses is simplified and takes the form:

$\sigma=\left[\begin{array}{ccc}\sigma_{1} & 0 & 0 \\ 0 & \sigma_{2} & 0 \\ 0 & 0 & \sigma_{3}\end{array}\right]$,

with $\sigma_{1}>\sigma_{2}>\sigma_{3}$.

The highest tangent stresses occur in the planes situated at the angle $45^{\circ}$ to the general directions and their value is equal to the half of difference of the respective main stresses:

$\tau_{1}=\frac{\sigma_{2}-\sigma_{3}}{2}, \tau_{2}=\frac{\sigma_{1}-\sigma_{3}}{2}, \tau_{3}=\frac{\sigma_{1}-\sigma_{2}}{2}$.

If the main stresses $\sigma_{1}, \sigma_{2}$ or $\sigma_{3}$ are equal: $\sigma_{1}=\sigma_{2}=\sigma_{3}$, so the tangent stresses $\tau_{1}=\tau_{2}=\tau_{3}=0$.

The stresses in any occurring cross-section, coming through the marked point of a body, may be determined by the main stresses and the directional cosinuses of the cross-section, i.e. the cosinuses of angles existing between a normal $n$ to the cross-section plane and the respective coordinate axes:

$\cos \angle(n, x)=f_{x}, \cos \angle(n, y)=f_{y}, \cos \angle(n, z)=f_{z}$,

with $\angle$ meaning angle, then the normal and tangent stresses are determined by the dependences:

$\sigma=f_{x}^{2} \sigma_{1}+f_{y}^{2} \sigma_{2}+f_{z}^{2} \sigma_{3}$

$\tau=\left[f_{x}^{2} \sigma_{1}+f_{y}^{2} \sigma_{2}+f_{z}^{2} \sigma_{3}-\left(f_{x}^{2} \sigma_{1}+f_{y}^{2} \sigma_{2}+f_{z}^{2} \sigma_{3}\right)^{2}\right]^{\frac{1}{2}}$.

The stress state in a point may be characterized by six independent parameters: three normal stresses and three tangent stresses, or three normal stresses and three directional cosinuses. The stress state, in which three main stresses act, is called a spatial, volumetric, or threedimensional state. The stress state in which only two main stresses act (the third one is equal to zero) is called a flat or two-dimensional state. In linear or one-dimensional state of stresses the only one, general stress is different from zero.

\section{Materials and method}

Carbon SteelC45 (JUSČ.1530, DIN C45, BS 080M46, GOST 45 AISI 1043, NF AF65C45, UNI C45) is the most popular material used in the industry. The
ANSYS meshed sample of cone is shown in Fig. 4 and the parameters and properties of ANSYS model of the studied C45 steel are demonstrated in Tab. 1.

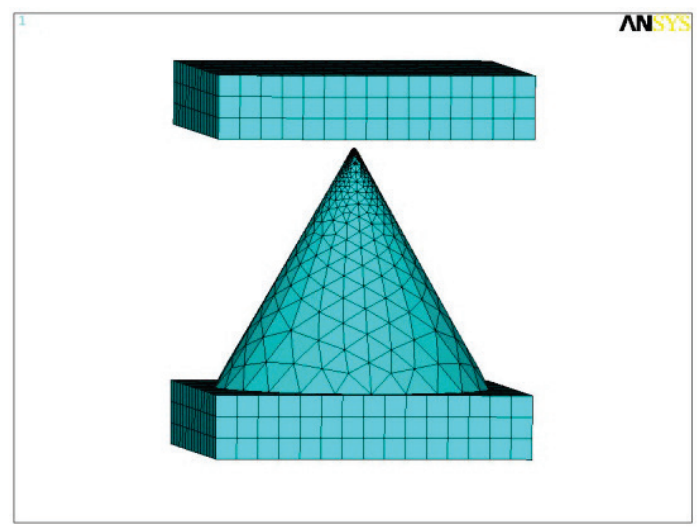

Figure 4 Meshed sample of cone deformation in ANSYS [13]

Table 1 Parameters and properties of the studied C45 steel for CooperSymonds material model [13]

\begin{tabular}{|c|c|}
\hline Parameters and properties of the steel & $\begin{array}{l}\text { Steel } \\
\text { C45 }\end{array}$ \\
\hline Density $\rho / \mathrm{kg} / \mathrm{m}^{3}$ & 7865 \\
\hline Young's modulus $E$ / GPa & 200 \\
\hline Poisson's ratio $v /-$ & 0.29 \\
\hline Strengthening parameter $\beta /-$ & 1 \\
\hline Yield stress $\sigma_{0} / \mathrm{MPa}$ & 342 \\
\hline $\begin{array}{l}\text { Material parameter depending the plastic strain } \\
\text { hardening } E_{\tan } / \mathrm{MPa}\end{array}$ & 241 \\
\hline $\begin{array}{l}\text { Material parameter defining the effect of intensity of } \\
\text { plastic strain rate } C / 1 / \mathrm{s}\end{array}$ & 5 \\
\hline $\begin{array}{l}\text { Material constatnt defining the material's sensitivity } \\
\text { to plastic strain rate } P /-\end{array}$ & 10 \\
\hline Failure strain / - & 0,75 \\
\hline
\end{tabular}

The ANSYS simulations were performed based on the five-level rotatable plan of experiment that is shown in Tab. 2.

Table 2 Five-level rotatable plan of experiment based on [12]

\begin{tabular}{|c|c|c|c|c|c|}
\hline \multicolumn{3}{|c|}{ Coded experiment design matrix } & \multicolumn{3}{|c|}{ Uncoded experiment design matrix } \\
\hline \multirow{3}{*}{ No } & $\alpha$ & $d$ & \multirow{3}{*}{ No } & $\alpha$ & $d$ \\
\hline & [Grad] & {$[\%]$} & & [Grad] & {$[\%$} \\
\hline & $\mathrm{A}$ & $\mathrm{B}$ & & $\mathrm{A}$ & $\mathrm{B}$ \\
\hline 1 & . & . & 1 & 60 & 10 \\
\hline 2 & 0 & - & 2 & 90 & 10 \\
\hline 3 & + & - & 3 & 120 & 10 \\
\hline 4 & - & 0 & 4 & 60 & 30 \\
\hline 5 & 0 & 0 & 5 & 90 & 30 \\
\hline 6 & + & 0 & 6 & 120 & 30 \\
\hline 7 & $\cdot$ & + & 7 & 60 & 50 \\
\hline 8 & 0 & + & 8 & 90 & 50 \\
\hline 9 & + & + & 9 & 120 & 50 \\
\hline
\end{tabular}

Uncoded experiment design matrix [settable values]

\begin{tabular}{|c|c|c|c|c|}
\hline \multirow{2}{*}{ No } & $\boldsymbol{\alpha}$ & $\boldsymbol{d}$ & \multicolumn{2}{|c|}{ Response: $\boldsymbol{S}$} \\
\cline { 2 - 5 } & {$[$ Grad] } & {$[\%]$} & \multicolumn{2}{|c|}{ [GPa] } \\
\cline { 2 - 5 } & $\mathrm{A}$ & $\mathrm{B}$ & Average & 1 \\
\hline 1 & 60 & 10 & 0,3793 & 0,3793 \\
\hline 2 & 90 & 10 & 0,379 & 0,379 \\
\hline 3 & 120 & 10 & 0,3369 & 0,3369 \\
\hline 4 & 60 & 30 & 0,3871 & 0,3871 \\
\hline 5 & 90 & 30 & 0,396 & 0,396 \\
\hline 6 & 120 & 30 & 0,4021 & 0,4021 \\
\hline 7 & 60 & 50 & 0,4075 & 0,4075 \\
\hline 8 & 90 & 50 & 0,4184 & 0,4184 \\
\hline 9 & 120 & 50 & 0,4643 & 0,4643 \\
\hline
\end{tabular}




\section{Results and discussion}

The shapes and deformations of cones as well as stress and strain are shown in Figs. 5, 6, 7, and 8. Maximum intensity of stresses for $10 \%$ strain of cone of the top angle $60^{\circ}$ equals $\sigma_{\max }=0,604 \mathrm{GPa}$, whereas the minimum stress $\sigma_{\min }=0,023 \mathrm{GPa}$. The substitute stresses were as follows: $\sigma_{z \max }=0,573 \mathrm{GPa}$ and $\sigma_{z \min }=0,02 \mathrm{GPa}$, respectively. The first degree stresses for $10 \%$ strain equal $\sigma_{1}=4,33 \mathrm{GPa}$, the second degree stresses equal $\sigma_{2}=$ 4,23 $\mathrm{GPa}$, whereas the third degree stresses equal $\sigma_{3}=$ $4,01 \mathrm{GPa}$. Deformations are equal to $\varepsilon=1,754$, and the substitute deformations $\varepsilon_{z}=1,677$.

Maximum intensity of stresses for $30 \%$ strain of sample of the top angle $60^{\circ}$ equals $\sigma_{\max }=0,587 \mathrm{GPa}$, whereas the minimum intensity of stress $\sigma_{\min }=0,186 \mathrm{GPa}$. Maximum substitute stresses for the studied sample were $\sigma_{z \max }=0,558 \mathrm{GPa}$, and minimum substitute stresses $\sigma_{z \min }=0,177 \mathrm{GPa}$. The first degree stresses for $30 \%$ strain equal $\sigma_{1}=3,42 \mathrm{GPa}$, whereas the second degree stresses are equal to $\sigma_{2}=3,35 \mathrm{GPa}$, and the third degree stresses equal $\sigma_{3}=2,87 \mathrm{GPa}$. Deformations values are $\varepsilon=1,906$, and the substitute deformations $\varepsilon_{z}=$ 1,721 (Fig. 6).
A
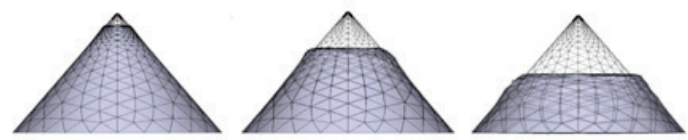

B

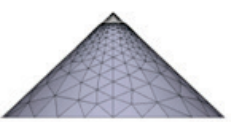

C

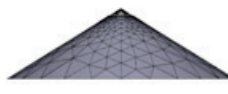

$10 \%$
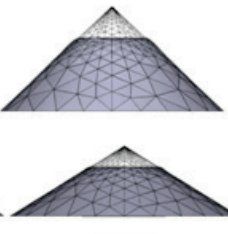

$30 \%$

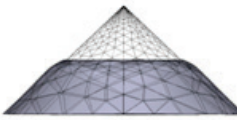

$50 \%$

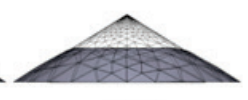

Figure 5 Shapes and deformations of cones of top angle: (A) $60^{\circ}$, (B) $90^{\circ},(\mathrm{C}) 120^{\circ}[13]$

Maximum intensity of stresses for $50 \%$ strain of sample of the top angle $60^{\circ}$ equals $\sigma_{\max }=0,586 \mathrm{GPa}$, whereas the minimum intensity of stress $\sigma_{\min }=0,200$ $\mathrm{GPa}$. Maximum substitute stresses for the studied sample were $\sigma_{z \max }=0,561 \mathrm{GPa}$, and minimum substitute stresses $\sigma_{z \min }=0,177 \mathrm{GPa}$. The first degree stresses for $50 \%$ strain equal $\sigma_{1}=3,63 \mathrm{GPa}$, whereas the second degree stresses are equal to $\sigma_{2}=3,59 \mathrm{GPa}$, and the third degree stresses equal $\sigma_{3}=2,87$.

The result of maximum intensity of stresses for $10 \%$ strain of cone of the top angle $90^{\circ}$ equals $\sigma_{\max }=0,467$ $\mathrm{GPa}$, whereas the minimum intensity of stresses $\sigma_{\min }=0,018 \mathrm{GPa}$. The substitute maximum stresses for the studied sample were $\sigma_{z \max }=0,451 \mathrm{GPa}$ and the minimum substitute stresses $\sigma_{z \min }=0,015 \mathrm{GPa}$. The first degree stresses for $10 \%$ strain equal $\sigma_{1}=2,94 \mathrm{GPa}$, whereas the second degree stresses are equal to $\sigma_{2}=2,92$ $\mathrm{GPa}$, and the third degree stresses equal $\sigma_{3}=2,72 \mathrm{GPa}$. The intensity of deformations equals $\varepsilon=1,113$, and the substitute deformations equal $\varepsilon_{z}=0,99$.

The result of maximum intensity of stresses for $30 \%$ strain of cone of the top angle $90^{\circ}$ equals $\sigma_{\max }=0,527$ $\mathrm{GPa}$, whereas the minimum intensity of stresses $\sigma_{\min }=0,112 \mathrm{GPa}$. The substitute maximum stresses for the studied sample were $\sigma_{z \max }=0.482 \mathrm{GPa}$ and the minimum substitute stresses $\sigma_{z \min }=0,098 \mathrm{GPa}$. The first degree stresses for $30 \%$ strain equal $\sigma_{1}=1,29 \mathrm{GPa}$, whereas the second degree stresses are equal to $\sigma_{2}=1,23$ $\mathrm{GPa}$, and the third degree stresses equal $\sigma_{3}=0,833 \mathrm{GPa}$. For the crush attempt the intensity of deformations equals $\varepsilon=1,128$, and the substitute deformations equal $\varepsilon_{z}=1,002$.

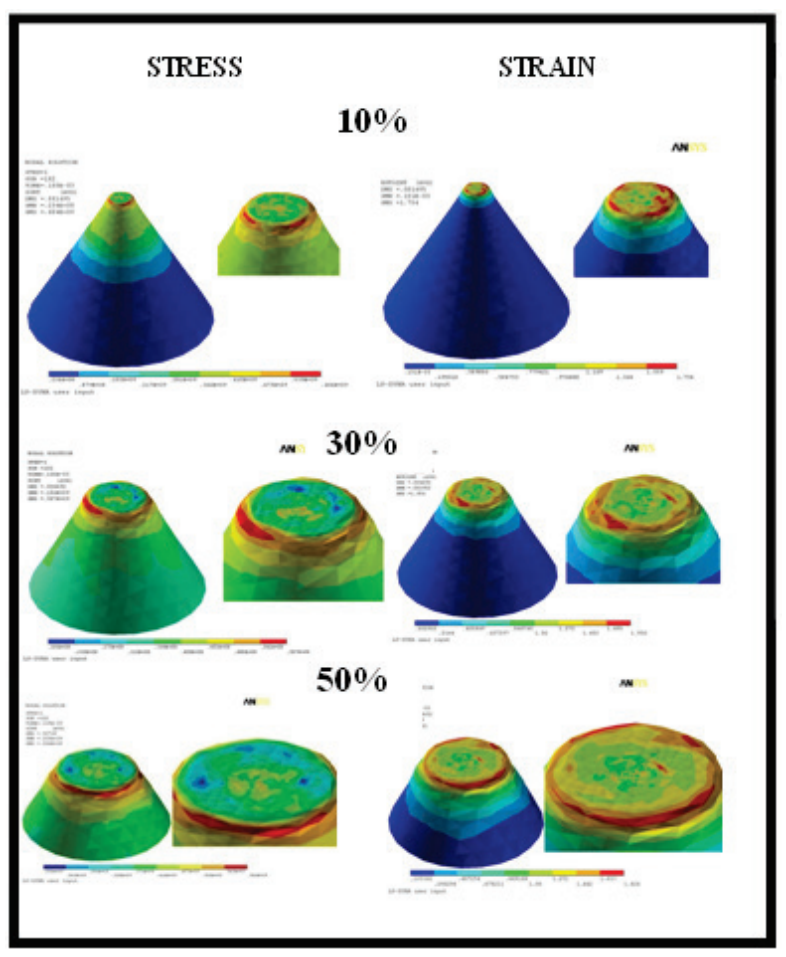

Figure 6 Results of stress and deformation intensity of cones of top angle $60^{\circ}$, with the flat punch and $10 \%, 30 \%$, and $50 \%$ strains [13]

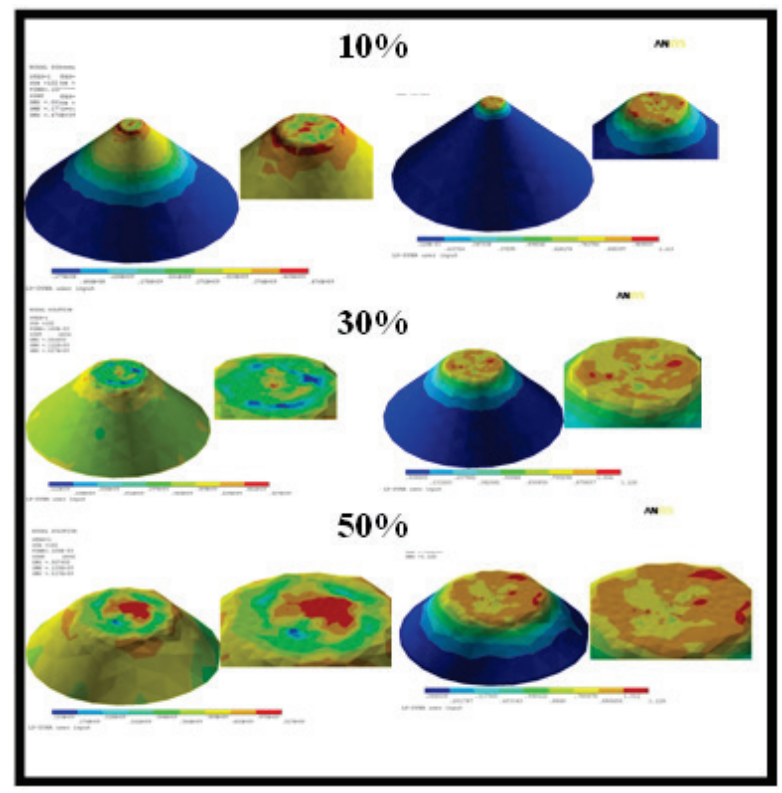

Figure 7 Results of stress and deformation intensity of cones of top angle $90^{\circ}$, with the flat punch and $10 \%, 30 \%$, and $50 \%$ strains [13]

The result of maximum intensity of stresses for $50 \%$ strain of cone of the top angle $90^{\circ}$ equals $\sigma_{\max }=0,517$ $\mathrm{GPa}$, whereas the minimum intensity of stresses $\sigma_{\min }=0,133 \mathrm{GPa}$. The substitute maximum stresses for the studied sample were $\sigma_{z \max }=0,459 \mathrm{GPa}$ and the minimum substitute stresses $\sigma_{z \min }=0,124 \mathrm{GPa}$. The first degree stresses for $50 \%$ strain equal $\sigma_{1}=0,928 \mathrm{GPa}$, 
whereas the second degree stresses are equal to $\sigma_{2}=0,896$ $\mathrm{GPa}$, and the third degree stresses equal $\sigma_{3}=0,478 \mathrm{GPa}$. The intensity of deformations for the studied sample equals $\varepsilon=1,128$, and the substitute deformations equal $\varepsilon_{z}$ $=1,026$ (Fig. 7).

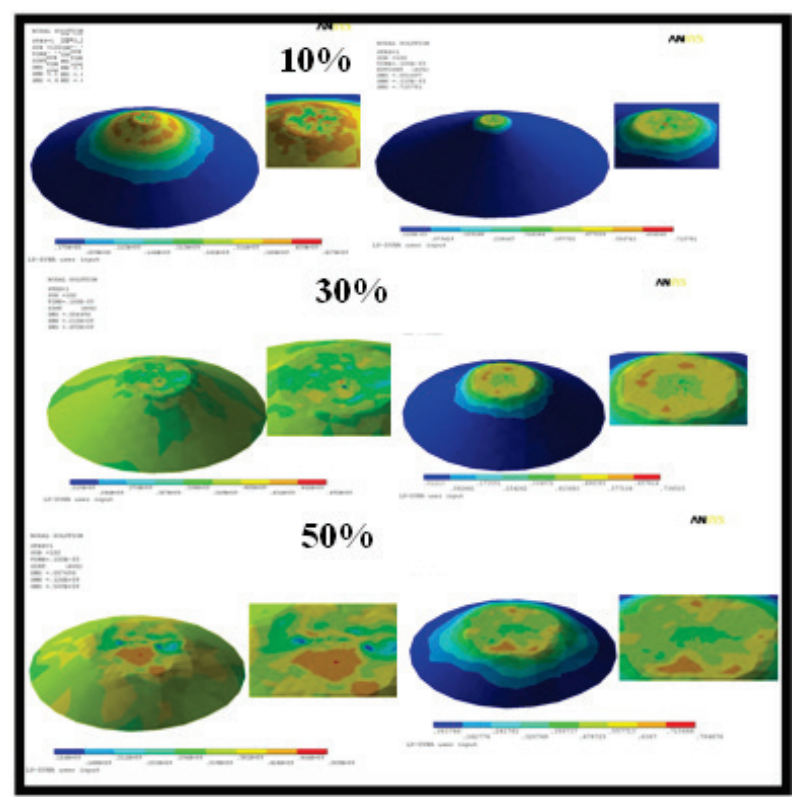

Figure 8 Results of stress and deformation intensity of cones of top angle $120^{\circ}$, with the flat punch and $10 \%, 30 \%$, and $50 \%$ strains [13]

The result of maximum intensity of stresses for $10 \%$ strain of cone of the top angle $120^{\circ}$ equals $\sigma_{\max }=0,457$ $\mathrm{GPa}$, whereas the minimum intensity of stresses $\sigma_{\min }=0,017 \mathrm{GPa}$. The substitute maximum stresses for the studied sample were $\sigma_{z \max }=0,432 \mathrm{GPa}$ and the minimum substitute stresses $\sigma_{z \min }=0,016 \mathrm{GPa}$. The first degree stresses for $10 \%$ strain equal $\sigma_{1}=0,769 \mathrm{GPa}$, whereas the second degree stresses are equal to $\sigma_{2}=0,612$ $\mathrm{GPa}$, and the third degree stresses equal $\sigma_{3}=0,466 \mathrm{GPa}$. The cone crush experiment shows that the intensity of deformations equals $\varepsilon=0,716$, and the substitute deformations equal $\varepsilon_{z}=0,701$.

The result of maximum intensity of stresses for $30 \%$ strain of cone of the top angle $120^{\circ}$ equals $\sigma_{\max }=0,493$ $\mathrm{GPa}$, whereas the minimum intensity of stresses $\sigma_{\min }=0,214 \mathrm{GPa}$. The substitute maximum stresses for the studied sample were $\sigma_{z \max }=0,442 \mathrm{GPa}$ and the minimum substitute stresses $\sigma_{z \min }=0,203 \mathrm{GPa}$. The results of first, second, and third degrees of stresses have been shown in Figs. 2, 3,4. The first degree stresses for $30 \%$ strain equal $\sigma_{1}=1,50 \mathrm{GPa}$, whereas the second degree stresses are equal to $\sigma_{2}=1,44 \mathrm{GPa}$, and the third degree stresses equal $\sigma_{3}=1,10 \mathrm{GPa}$. The cone crush experiment shows that the intensity of deformations equals $\varepsilon=0,738$, and the substitute deformations equal $\varepsilon_{z}=0,759$.

The maximum intensity of stresses for $50 \%$ strain of cone of the top angle $120^{\circ}$ equals $\sigma_{\max }=0,509 \mathrm{GPa}$, whereas the minimum intensity of stresses $\sigma_{\min }=0,126 \mathrm{GPa}$. The substitute maximum stresses for the studied sample were $\sigma_{z \max }=0,457 \mathrm{GPa}$ and the minimum substitute stresses $\sigma_{z \min }=0,110 \mathrm{GPa}$. The first degree stresses for $50 \%$ strain equal $\sigma_{1}=0,688 \mathrm{GPa}$, whereas the second degree stresses are equal to $\sigma_{2}=0,564$
$\mathrm{GPa}$, and the third degree stresses equal $\sigma_{3}=0,378 \mathrm{GPa}$. The cone crush experiment shows that the intensity of deformations equals $\varepsilon=0,795$, and the substitute deformations equal $\varepsilon_{z}=0,704$.

The complete results ordered by the five-level rotatable statistical plan are given in Tab. 3. Fig. 9 shows the plane graph with mathematical formula which described about $87 \%$ of the points obtained by ANSYS simulation (Tab. 3). Based on this data processing there was noticed that under the cone deformation the top angle has a significant effect on the stress and strain in the deformed surface layer. It was found that at the top angle of $120^{\circ}$ and at $50 \%$ deformation the highest stress was obtained.

Table 3 Five-level rotatable plan of experiment based on [12]
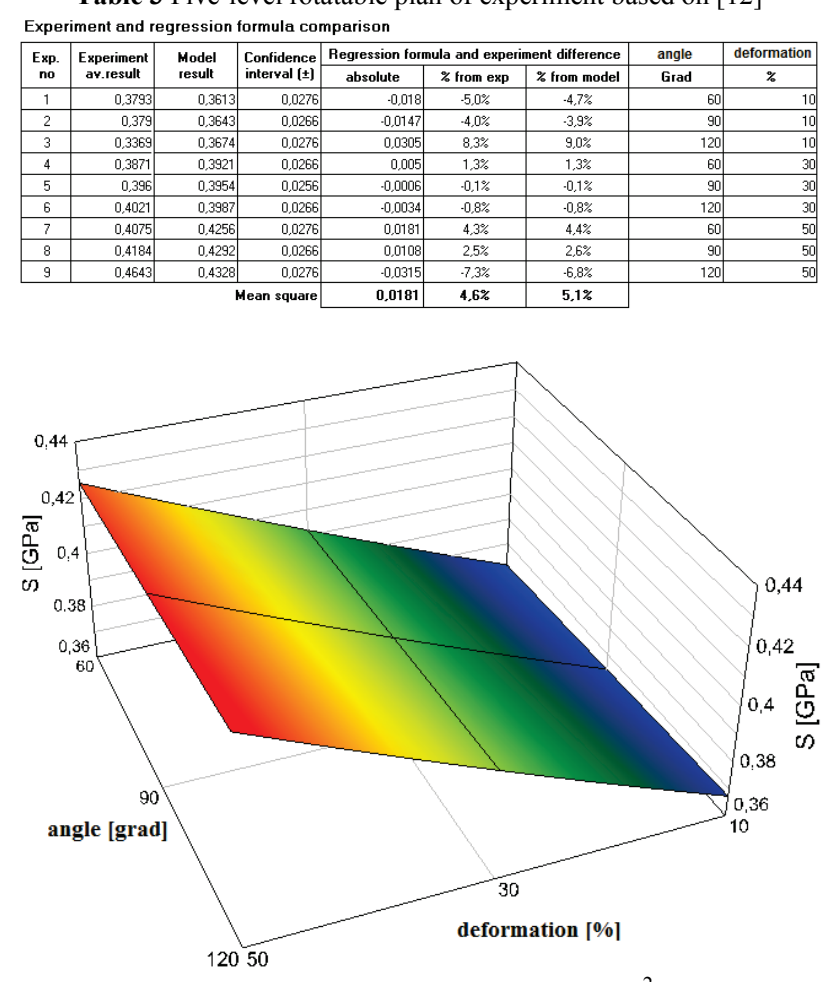

$S=\exp (-1,075+0,0003 \cdot \alpha+0,0041 \cdot d), R^{2}=0,87$

where: $S$-stress, $\alpha$ - angle, $d$ - deformation

Figure $93 \mathrm{D}$ plot of influence of the deformation on stress

\section{Conclusion}

The following conclusions may be formulated after the studies:

- Under the cone deformation, the top angle has a significant effect on the strain in the deformed surface layer

- Under the cone deformation, the top angle has a significant effect on the stress in the deformed surface layer

- The highest stress was obtained at the top angle $120^{\circ}$ and at $50 \%$ deformation.

\section{Acknowledgment}

Experiments were carried out partly by DAADForschungsaufenthalt für Hochschullehrer und Wissenschaftler (DAAD research stays for University Academics and Scientists). This paper has been 
elaborated in the framework of the Moravian-Silesian Region project no. RRC/01569/2012 and the project RMTVC no. CZ.1.05/2.1.00/01.0040. Thanks also go to the IT4Innovations Centre of Excellence project, reg. no. CZ.1.05/1.1.00/02.0070.

\section{$5 \quad$ References}

[1] Kułakowska, A.; Kukiełka, L. Numerical analysis and experimental researches of burnishing rolling process with taking into account deviations in the surface asperities outline after previous treatment. $/ 12^{\text {th }}$ International Conference on Metal Forming, Cracow, Poland. // Steel Research International. 2008, pp. 42-48.

[2] Patyk, R.; Kukiełka, L. Optimization of geometrical parameters of regular triangular asperities of surfaces put to smooth burnishing. / $12^{\text {th }}$ International Conference on Metal Forming, Cracow, Poland. // Steel Research International. 2008, pp. 642-647.

[3] Kukiełka, L.; Chodor, J.; Storch, B. New method of determination of the tool rake angle on the basis of the crack angle of the specimen in tensile tests and numerical simulations. $/ 9^{\text {th }}$ International Conference on Surface Effects and Contract Mechanics, Algarve, Portugal. Surface Effects and Contact Mechanics, IX Book Series: // WIT Transactions on Engineering Sciences. 2009, pp. 207-216.

[4] Kukiełka, L.; Kukiełka, K. Numerical analysis of the physical phenomena in the working zone in the rolling process of the round thread. // Transactions on Engineering Sciences. 55, (2007), pp. 125-134. DOI: 10.2495/SECM070121

[5] Kukiełka, L.; Chodor, J. Numerical analysis of the influence of abrasive grain geometry and cutting angle on states of strain and stress in the surface layer of object. // Transactions on Engineering Sciences. 55, (2007), 183193. DOI: $10.2495 /$ SECM070181

[6] Kukiełka, L.; Kukiełka, K. Numerical analysis of the process of trapezoidal thread rolling. // Transactions on the Built Environment. 85, (2006), pp. 663-672. DOI: 10.2495/HPSM06065

[7] Kukiełka, L.; Kustra, J.; Kukiełka, K. Numerical analysis of states of strain and stress of material during machining with a single abrasive grain. $/ 7^{\text {th }}$ International Conference on Computer Methods and Experimental Measurements for Surface Effects and Contact Mechanics, Bologna, Italy. // Transactions on Engineering Sciences. 49, (2005), pp. 5766.

[8] Kukiełka, L. Numerical modeling: the contact problem of movable elasto/visco-plastic body. $/ / 6^{\text {th }}$ International Conference on Computational Methods in Contact Mechanics, Iraklion, Greece. Computational and Experimental Methods. 8, (2003), pp. 93-102.

[9] Kukiełka, L.; Kustra, J. Numerical analysis of thermal phenomena and deformations in processing zone in the centerless continuous grinding process. $/ / 6^{\text {th }}$ International Conference on Computational Methods in Contact Mechanics, Iraklion, Greece. Computational and Experimental Methods. 7, (2003), pp. 109-118.

[10] Kukiełka, L. Non-linear analysis of heat transfer in burnishing rolling operation. $/ / 7^{\text {th }}$ International Conference on Advanced Computational Methods in Heat Transfer, Halkidiki, Greece. Computational Studies. 4, (2002), pp. 405-414.

[11] Kukiełka, L. Mathematical modelling and numerical simulation of non-linear deformation of the asperity in the burnishing cold rolling operation. / $5^{\text {th }}$ International Conference on Computational Methods in ContactMechanics, Sevilla, Spain. // Computational and Experimental Methods. 5, (2001), pp. 317-326.
[12] Kukiełka, L. Fundamentals of Engineering Studies (Podstawy badań inżynierskich), Publisher: PWN, 2002, ISBN: 83-01-13749-5

[13] Rypina, Ł. Analiza wpływu zgniotu stożka na odporność korozyjną powierzchni po deformacji, Master'sThesis, Faculty of Mechanical Engineering, Koszalin University of Technology, 2007.

[14] Kleiber, M. Metoda elementów skończonych w nieliniowej mechanice kontinuum, Biblioteka Mechaniki Stosowanej Instytut Podstawowych Problemów Techniki PAN, PWN, Warszawa-Poznań 1985. ISBN: 83-01-05051-9.

[15] Ostrowska-Maciejewska, J. Mechanika Ciał Odkształcalnych, PWN, Warszawa, 1994.

[16] Fung, Y. C. Podstawy Mechaniki Ciała Stałego, PWN, Warszawa 1969, ISBN: 83-01-11415-0.

[17] Valiček, J.; Drzik, M.; Hryniewicz, T.; Harničarova, M.; Rokosz, K.; Kusnerova, M.; Barcova, K.; Brazina, D. Noncontact method for surface roughness measurement after machining. // Measurement Science Review. 12, 5(2012), pp. 184-188. DOI: 10.2478/v10048-012-0028-3

[18] Kusnerova, M.; Valiček, J.; Harničarova, M.; Hryniewicz, T.; Rokosz, K.; Palkova, Z.; Vaclavik, V.; Repka, M.; Bendova, M. A proposal for simplifying the method of evaluation of uncertainties in measurement results. // Measurement Science Review. 13, 1(2013), pp. 1-6. DOI: 10.2478/msr-2013-0007

[19] Szarkova, V.; Valiček, J.; Vlado, M.; Harničarova, M.; Rokosz, K.; Luptak, M.; Samardzic, I.; Kozak, D.; Hloch, $\mathrm{S}$. Influence of longitudinal cold rolling on the surface topography of low carbon structural steel. // Tehnicki vjesnik-Technical Gazette. 20, 4(2013), pp. 705-709.

\section{Authors' addresses}

\section{Krzysztof Rokosz}

Tadeusz Hryniewicz (corresponding author)

Division of Surface Electrochemistry and Engineering

Faculty of Mechanical Engineering,

Koszalin University of Technology

Racławicka 15-17, PL 75-620 Koszalin, Poland

E-mail: rokosz@tu.koszalin.pl

E-mail: Tadeusz.Hryniewicz@tu.koszalin.pl

\section{Winfried Malorny}

Baustoffkunde, Bautenschutz/Sanierungsbaustoffe, Bauphysik

Bereich Bauingenieurwesen, Hochschule Wismar

Philip-Müller-Straße 14, DE 23966 Wismar, Germany

E-mail: winfried.malorny@hs-wismar.de

\section{Jan Valiček}

Marta Harničárová

Institute of Physics,

Nanotechnology Centre, VŠB - Technical University of Ostrava,

17. listopadu 15/2172, 70833 Ostrava-Poruba, Czech Republic

E-mail: jan.valicek@vsb.cz

E-mail: marta.harnicarova@vsb.cz 